\title{
Seismic hazard map of the western hemisphere
}

\author{
Kaye M. Shedlock $\left({ }^{1}\right)$ and James G. Tanner $\left(^{2}\right)$ \\ ( $\left.{ }^{1}\right)$ U.S. Geological Survey, Golden, CO, U.S.A. \\ $\left.{ }^{(}\right)$University of Western Ontario, ON, Canada
}

\begin{abstract}
Vulnerability to natural disasters increases with urbanization and development of associated support systems (reservoirs, power plants, etc.). Catastrophic earthquakes account for $60 \%$ of worldwide casualties associated with natural disasters. Economic damage from earthquakes is increasing, even in technologically advanced countries with some level of seismic zonation, as shown by the 1989 Loma Prieta, CA (\$ 6 billion), 1994 Northridge, CA ( $\$ 25$ billion), and 1995 Kobe, Japan (> \$ 100 billion) earthquakes. The growth of megacities in seismically active regions around the world often includes the construction of seismically unsafe buildings and infrastructures, due to an insufficient knowledge of existing seismic hazard. Minimization of the loss of life, property damage, and social and economic disruption due to earthquakes depends on reliable estimates of seismic hazard. National, state, and local governments, decision makers, engineers, planners, emergency response organizations, builders, universities, and the general public require seismic hazard estimates for land use planning, improved building design and construction (including adoption of building construction codes), emergency response preparedness plans, economic forecasts, housing and employment decisions, and many more types of risk mitigation. The seismic hazard map of the Americas is the concatenation of various national and regional maps, involving a suite of approaches. The combined maps and documentation provide a useful global seismic hazard framework and serve as a resource for any national or regional agency for further detailed studies applicable to their needs. This seismic hazard map depicts Peak Ground Acceleration (PGA) with a 10\% chance of exceedance in 50 years for the western hemisphere. PGA, a short-period ground motion parameter that is proportional to force, is the most commonly mapped ground motion parameter because current building codes that include seismic provisions specify the horizontal force a building should be able to withstand during an earthquake. This seismic hazard map of the Americas depicts the likely level of short-period ground motion from earthquakes in a fifty-year window. Short-period ground motions effect short-period structures (e.g., one-to-two story buildings). The largest seismic hazard values in the western hemisphere generally occur in areas that have been, or are likely to be, the sites of the largest plate boundary earthquakes. Although the largest earthquakes ever recorded are the 1960 Chile and 1964 Alaska subduction zone earthquakes, the largest seismic hazard (PGA) value in the Americas is in Southern California (U.S.), along the San Andreas fault.
\end{abstract}

Key words seismic hazard assessment - NorthSouth America - earthquakes - UN/IDNDR

\section{Introduction}

Seismic hazard maps depict the levels of chosen ground motions that likely will, or will not, be exceeded in specified exposure times.

Mailing address: Dr. Kaye M. Shedlock, U.S. Geological Survey, Golden, CO 80225, U.S.A.; e-mail: shedlock@ gldmutt.cr.usgs.gov
Hazard assessment programs in the region commonly specify a $10 \%$ chance of exceedance $(90 \%$ chance on non-exceedance) of some ground motion parameter for an exposure time of 50 years, corresponding to a return period of 475 years. Commonly mapped ground motions are maximum intensity, Peak Ground Acceleration (PGA), Peak Ground Velocity (PGV), and several Spectral Accelerations (SA). Each ground motion mapped corresponds to a portion of the bandwidth of energy radiated from an earthquake. PGA and $0.2 \mathrm{~s} \mathrm{SA}$ correspond to shortperiod energy that will have the greatest effect 
on short-period structures (one-to two story buildings, which is the most common building stock in the region). Longer-period SA maps $(1.0 \mathrm{~s}, 2.0 \mathrm{~s}$, etc.) depict the level of shaking that will have the greatest effect on longer-period structures ( $10+$ story buildings, bridges, etc.).

Each national or regional seismic hazard map in the Americas was produced using the methodology originally described by Cornell (1968).
There are three major elements of this method: 1) the characterization of seismic sources; 2) the characterization of attenuation of ground motion; and 3) the actual calculation of probabilities. Variations in each element of seismic hazard assessment lead to differences in the estimated hazard along the national borders in North America. The hazard values for Central and South America were computed regionally, re-

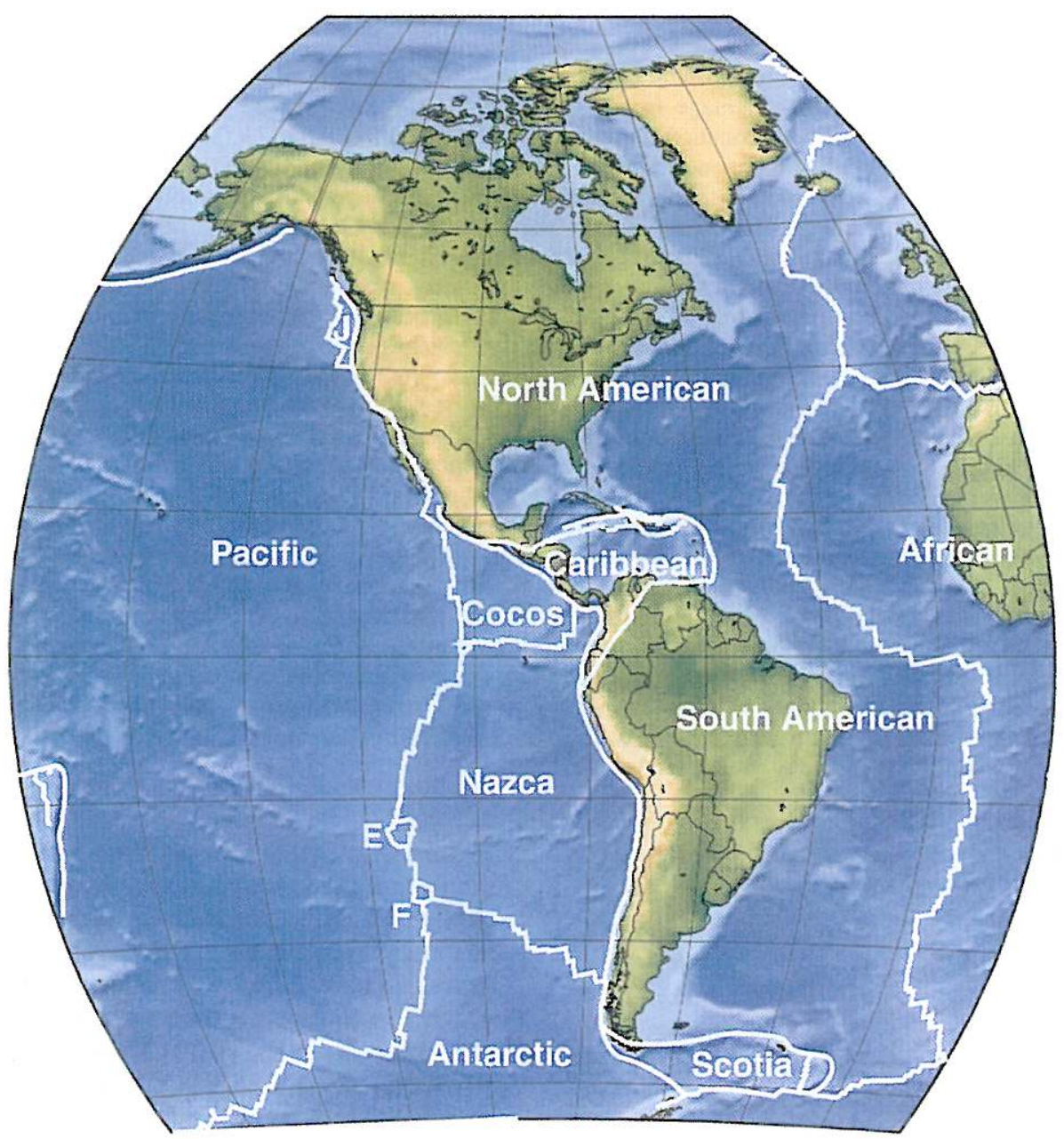

Fig. 1. The major tectonic plates of the Americas are named in white letters. The « $\mathrm{J} »$ denotes the Juan de Fuca and the smaller Explorer (north) and Gorda (south) plates. The «E» denotes the Easter plate. The «F» denotes the Juan Fernandez plate. The small Rivera plate abuts the Cocos plate on the northwest. 


\section{Temporal Range of Deformation Data}

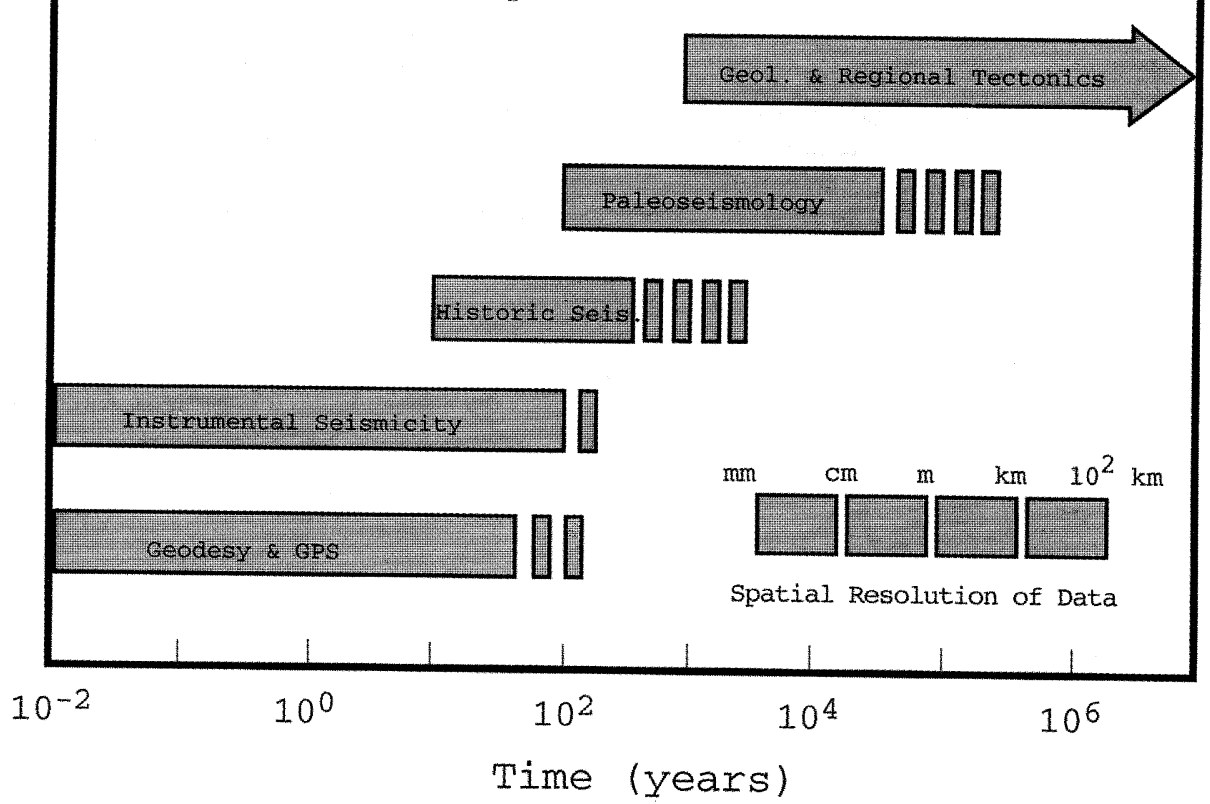

Fig. 2. Earthquake catalogs (instrumental and historical), geodetic monitoring, and GPS measurements provide data on the order of tens to hundreds of years. Paleoseismology, geology, and regional tectonic studies extend the temporal range of information into the thousands, and possibly tens of thousands of years. These different types of data also provide spatial resolution of deformation at different scales. For example, GPS data provide spatial resolution of deformation on the order of centimeters, while historic seismicity data provide resolution of deformation on the order of tens to hundreds of kilometers. Seismographs and strong motion instruments (instrumental seismicity) record deformation on the order of millimeters and centimeters, although the information gleaned from instrumental seismicity (locations) can provide deformation information over distances of kilometers. (Figure provided by E. Schweig).

sulting in continuous hazard contours across national boundaries.

The first element of seismic hazard assessment, the characterization of seismic sources, involves obtaining 'robust' answers to three questions:

- Where do earthquakes occur?

- How often do earthquakes occur? to be?

- How big can we expect these earthquakes

Ninety percent $(90 \%)$ of all earthquakes occur along the plate boundaries (fig. 1). The Americas are the major landmasses of three plates (North and South American and Caribbean).
Almost all of the known major earthquakes in the Americas have occurred along the western edges of these three plates, where they are overriding or sliding past the Pacific, Cocos, Nazca, and associated smaller plates (fig. 1). Seismicity catalogs are the fundamental tool used to determine where, how often, and how big earthquakes are likely to be. However, seismicity statistics are based on geologically short catalogs, so other deformation data are examined (fig. 2).

The results from seismic monitoring, the historic record, geodetic monitoring, and the geologic record are combined to characterize seismic sources. Most countries in the Americas 


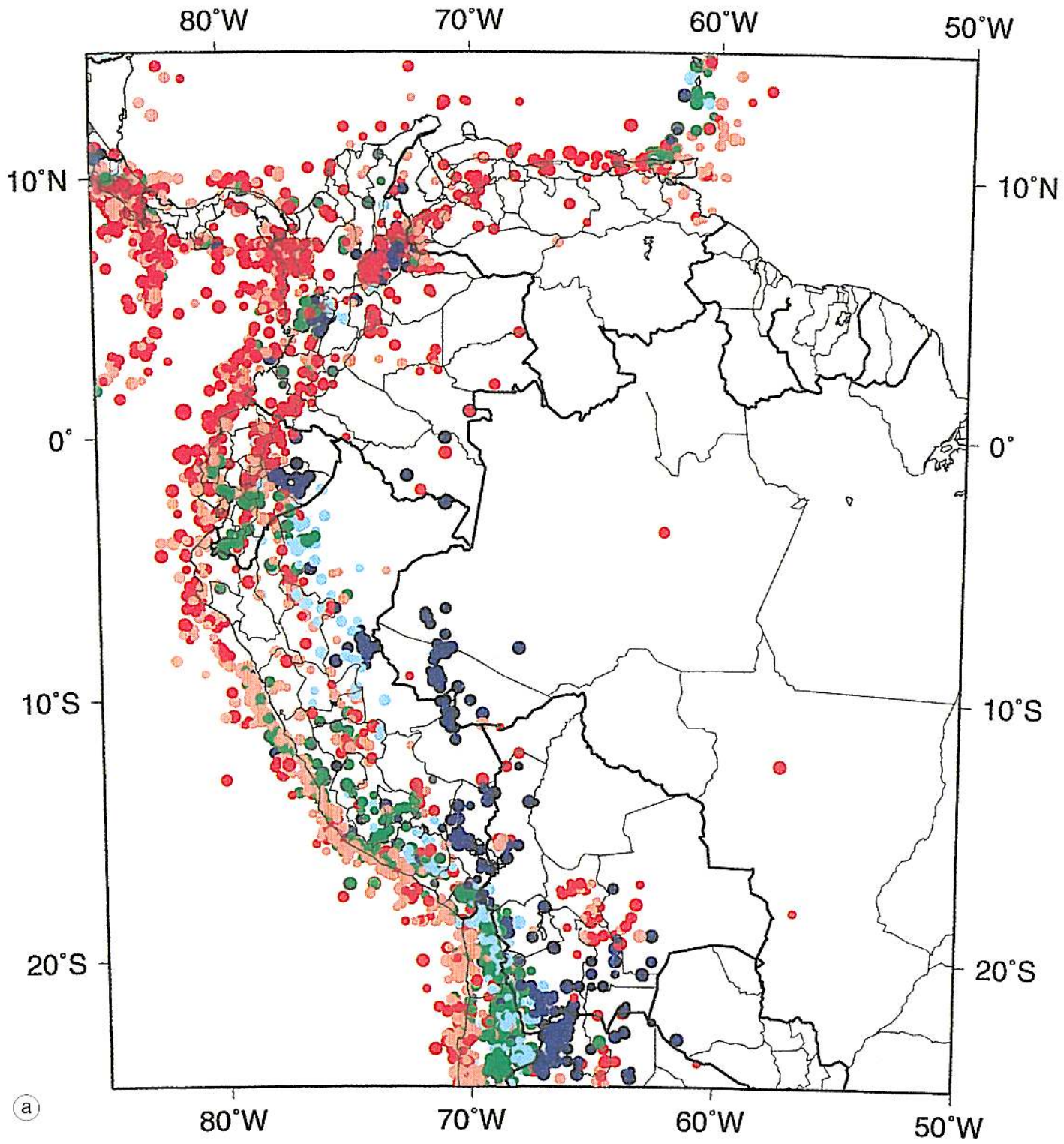

Fig. 3a,b. Seismicity and seismic zones for South America determined by the Pilot Project for Regional Earthquake Monitoring and Seismic Hazard Assessment (PILOTO). a) South America seismicity, 1471-1994. $M=5.0$. Sizes of the dots are scaled to magnitude. Colors of the dots denote depths: red $=0-30 \mathrm{~km}$, pink $=$ $30-70 \mathrm{~km}$, green $=70-110 \mathrm{~km}$, light blue $=110-150 \mathrm{~km}$, and blue $=150 \mathrm{~km}$. b) Seismic zones used to calculate 


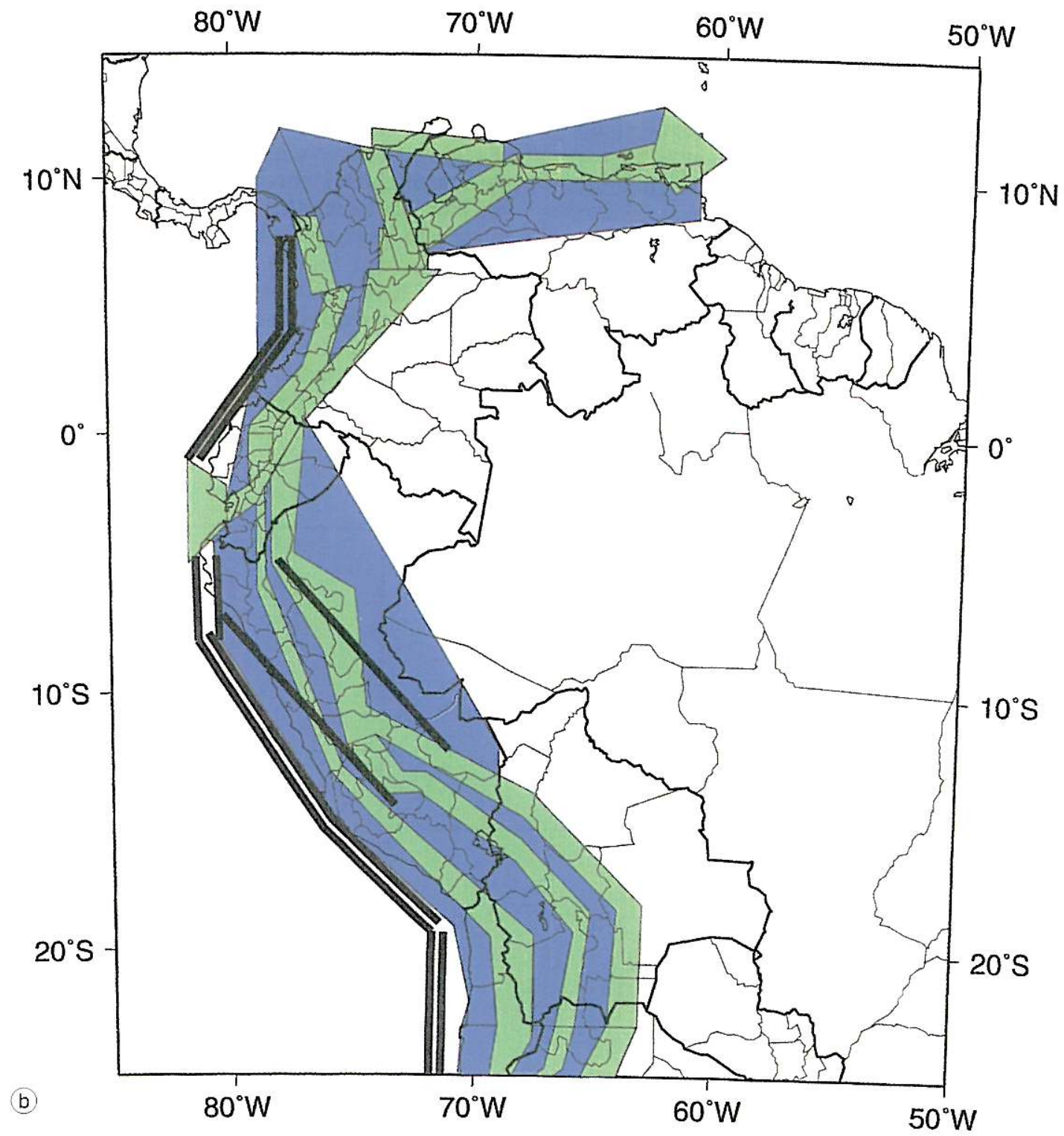

the hazard values for South America. The blue zones are 'background' zones, where the seismicity is not well defined. The green zones are 'seismogenic' zones, where the seismicity is well defined, and often associated with distinct tectonic structures. The heavy black lines are subduction zones, modeled as faults for hazard calculations. (Figure modified from Dimaté et al., 1999). 
use these data to interpret seismic source zones (fig. 3a,b). Because many interpretations of the input data are possible, there are large uncertainties associated with source characterization. Various schemes are invoked to either explicitly or implicitly include these uncertainties in seismic hazard calculations. For example, multiple source zone models may be defined. Hazard calculations from each model are then combined using various schemes that produce a weighted mean (or median) hazard value.

State-of-the-art estimates of expected ground motion at a given distance from an earthquake of a given magnitude are the second element of earthquake hazard assessments. These estimates are usually equations, called attenuation relationships, which express ground motion as a function of magnitude and distance (and occasionally other variables, such as type of faulting). Ground motion attenuation relationships (fig. 4) may be determined in two different ways: empirically, using previously recorded ground motions, or theoretically, using seismological models to generate synthetic ground motions which account for the source, site, and path effects. There is overlap in these approaches, however, since empirical approaches fit the data to a functional form suggested by theory and theoretical approaches often use empirical data to determine some parameters.

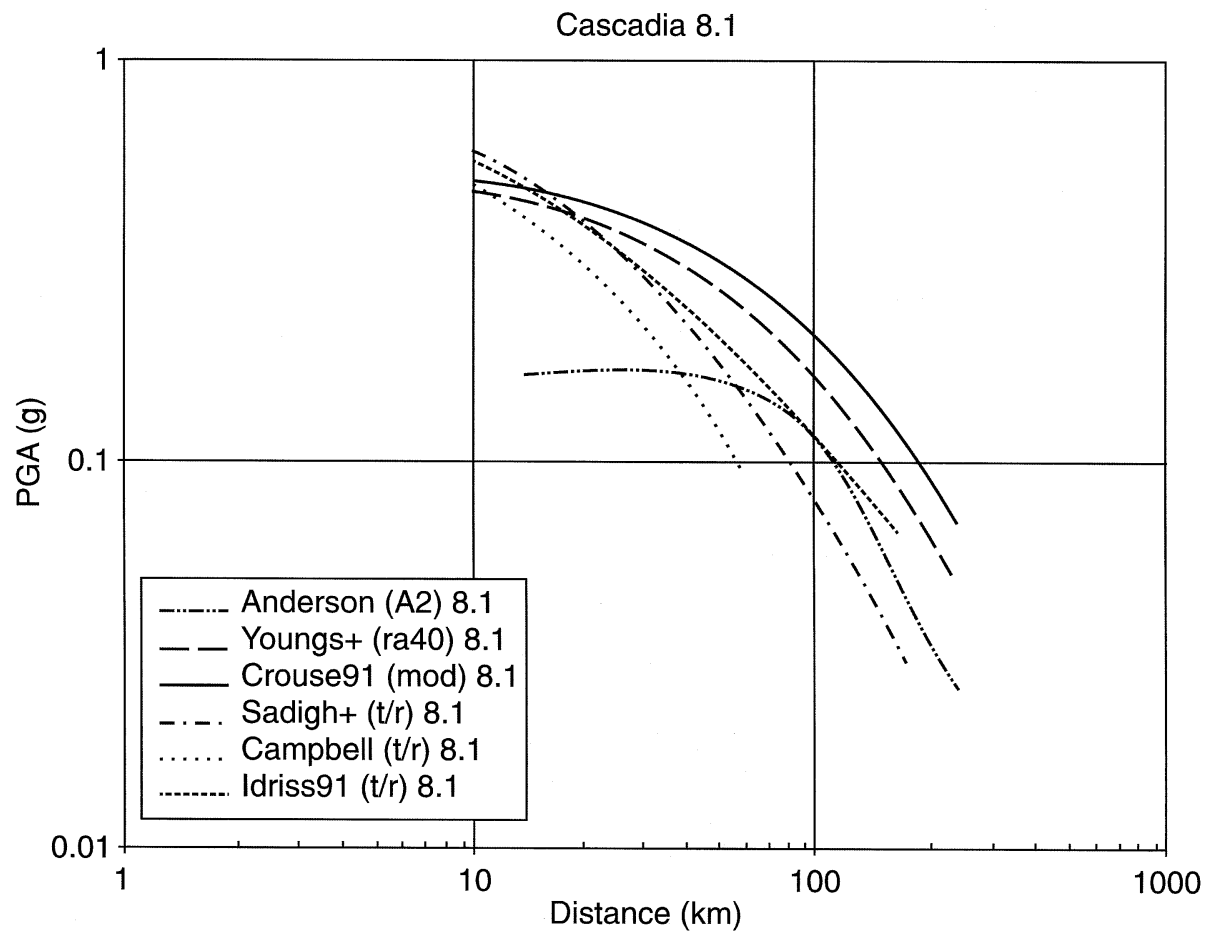

Fig. 4. An example of a suite of attenuation relationships. Peak Ground Acceleration (PGA), in units of $g$, predicted by six attenuation relationships for an $\boldsymbol{M} 8.1$ earthquake in the Cascadia (Western North America) region. $(t / r)$ means the values are predicted for a thrust or reverse earthquake; + signifies that there are co-authors of the functions; (A2) refers to the model designation given by Anderson (1997); (ra40) means that the values are calculated assuming an intraslab earthquake at $40 \mathrm{~km}$ hypocentral depth; (mod) signifies that the values are calculated from the modified version of the Crouse (1991) relationships. (Figure is taken from Shedlock and Abrahamson, 1997.) 
The parameters that must be clearly defined in order to estimate ground motions are: earthquake magnitude, type of faulting, distance, and local (receiver) site conditions (classification). Moment magnitude $(\boldsymbol{M})$ is the preferred magnitude measure, because it is directly related to the seismic moment of the earthquake and does not saturate. Style of faulting needs to be specified because, within $100 \mathrm{~km}$ of a site, strikeslip earthquakes generate smaller ground motions than reverse and thrust earthquakes, except for $\boldsymbol{M} \cdot 8.0$ (Boore et al., 1993, 1994; Campbell and Bozorgnia, 1994). Different researchers use different source-to-site distance measures. A complete summary can be found in Abrahamson and Shedlock (1997). There are also several site classification schemes, ranging from a description of the physical properties of near-surface material to very quantitative characterizations. Seismic hazard maps are calculated for a specific site classification (hard rock, soft rock, stiff soil, soil, soft soil, etc.). Hazard values calculated for rock/stiff soil sites (the most common site classifications) are lower than hazard values calculated for soil sites. Often, hazard values for soil sites my be estimated from the rock/stiff soil site values commonly depicted on hazard maps through multiplication by a specified factor, but these are no more than rough estimates. Summaries may be found in Borcherdt (1993) and Shedlock and Abrahamson (1997).

The third element of hazard assessment, the actual calculation of expected ground motion values, involves determining an annual frequency of exceedance of the ground motion parameter of interest, then summing over the time period of interest. The most commonly mapped ground motion parameters are horizontal and vertical Peak Ground Acceleration (PGA), Peak Ground Velocity (PGV), and 5\%-damped Spectral Acceleration (SA) for a given site classification. Historically, maps of PGA values have formed the basis of seismic zone maps that are included in building codes, including the U.S. Uniform Building Code. Current building codes that include seismic provisions specify the horizontal force a building should be able to withstand during an earthquake. PGA values are directly related to the lateral forces that damage short period structures (a single-family dwelling, i.e. the most common structure in any country). Maps of longer period spectral response ordinates $(0.3 \mathrm{~s}, 0.5 \mathrm{~s}, 1.0 \mathrm{~s}, 2.0 \mathrm{~s}$, etc. $)$ are directly related to the lateral forces that damage larger structures with longer natural periods (apartment buildings, hi-rises, bridges).

The PGA seismic hazard map of the Americas is the concatenation of various national and regional maps, involving a suite of approaches. The methods and data used in the generation of each national or regional map used to produce the seismic hazard map of the western hemisphere are documented briefly herein, along with the names and contact information for the scientists responsible for the maps. The user is encouraged to contact the appropriate scientists and/or agencies for more detailed information.

\section{North and Central America and the Caribbean}

Shedlock (1999) presents a summary of the data and methods used to produce the seismic hazard map of North and Central America and the Caribbean.

\section{South America}

Various researchers have published probabilistic seismic hazard maps of countries or regions of South America. Centro Regional de Sismologia para America del Sur (CERESIS) was established in 1971 to coordinate and increase the observation, recording, analysis, and interpretation of seismicity in South America. CERESIS published the first regional seismicity catalogs and hazard maps in 1981. A complete summary of the current CERESIS seismic hazard map may be found elsewhere (http://seismo.ethz.ch/GSHAP). CERESIS also cooperated with the Pan-American Institute of Geography and History (PAIGH) to produce a seismic hazard map of the region (Tanner and Shepherd, 1997). In 1995, researchers from four European-Mediterranean (EUME) and five Andean Pact (JUNAC) countries formed the 
Pilot Project for Regional Earthquake Monitoring and Seismic Hazard Assessment (PILOTO). Among the many achievements of this group is a Andean region seismic hazard map. A complete summary of the PILOTO seismic hazard map may be found elsewhere in this volume (Dimate et al., 1999). The seismic hazard map of South America included in this report is a combination of the maps produced under the auspices of PAIGH and PILOTO. Herein, we describe the data and methods used to produce the PAIGH and the combined seismic hazard maps.

\subsection{Seismicity}

Seismicity in South America is concentrated along the South American/Caribbean/Cocos/ Nazca (and associated smaller) plate boundaries (fig. 5). The largest earthquake ever recorded occurred along the coast of Chile in 1960 $(\boldsymbol{M}=9.5$; Kanamori, 1977). During the twentieth century, earthquakes with $\boldsymbol{M}>8$ have been recorded along the coasts of Ecuador (1906), Chile (1906, 1922, and 1943) and Peru (1940, 1942, 1966, and 1974).

The historical catalog for the region begins in 1471. The instrumental recording of earthquakes began in the early 1900's, but the deployment of national seismograph networks in the countries of South America occurred in the 1960's. The catalog used for the hazard map calculations contained all earthquakes with $\boldsymbol{M}>4.0$ that occurred between 1900 and 1994. All magnitudes were converted to moment magnitude $(\boldsymbol{M})$ through a multi-step process (Tanner and Shepherd, 1997). As a first step in their conversion scheme, Tanner and Shepherd (1997) obtained the seismic moment $\left(M_{0}\right)$ of as many of the earthquakes in the catalog as possible. For most of the large earthquakes that occurred prior to the 1980 's, $M_{0}$ has been derived from the relationship

$$
M_{0}=\mu A d
$$

where $\mu$ is the shear modulus (rigidity), $A$ is the area of the fault plane, and $d$ is the average slip during the earthquake (Aki and Richards, 1980). Tanner and Shepherd (1997) then converted $M_{0}$ to $\boldsymbol{M}$ using the relationship

$$
\boldsymbol{M}=2 / 3 \log M_{0}-10.73
$$

derived by Kanamori (1977). The hierarchical scheme developed by Tanner and Shepherd (1997) to assign $\boldsymbol{M}$ values to all the earthquakes in the catalog is:

- $\boldsymbol{M}$ calculated from $M_{0}$, where $M_{0}$ was determined directly from the Aki and Richards (1980) relationship.

- $\boldsymbol{M}$ calculated from $M_{0}$, where $M_{0}$ was determined directly from digital, broadband seismic records.

- $\boldsymbol{M}$ from $M_{0}$, where $M_{0}$ was taken directly from the Harvard University CMT catalog.

- $\boldsymbol{M} \approx M_{S}$ where $M_{S}$ has been reliably determined for $M_{s}>6.6$ and $\boldsymbol{M}=2 / 3 M_{s}+2.34$ for $M_{S} \leq 6.6$.

- $\boldsymbol{M}$ calculated from $m_{b}$ through a two-step process of first converting $m_{b}$ to $M_{s}$ using $M_{S}=1.74 m_{b}-3.95$, then using one of the relationships given above.

- $\boldsymbol{M}$ calculated from other magnitude scales through a two-step process of first converting the other magnitude to $M_{S}$ using one of several known relationships, then using one of the relationships given above.

Any earthquakes with magnitudes that could not be converted to $\boldsymbol{M}$ using the above hierarchy were excluded from the catalog. The catalog may be considered complete at three levels: $\boldsymbol{M} \geq 7.0$ for $1900-1994 ; \boldsymbol{M} \geq 6.5$ for 1938-1994; and $\boldsymbol{M} \geq 4.3$ for 1964-1994 (Tanner and Shepherd, 1997).

\subsection{Source characterization}

The PAIGH Project Steering Committee chose the historic parametric method (described below) to generate their seismic hazard map of South America. Thus, the earthquake catalog for the region served as the source characterization for the seismic hazard map. No geologic information was used. No source zones were drawn. 


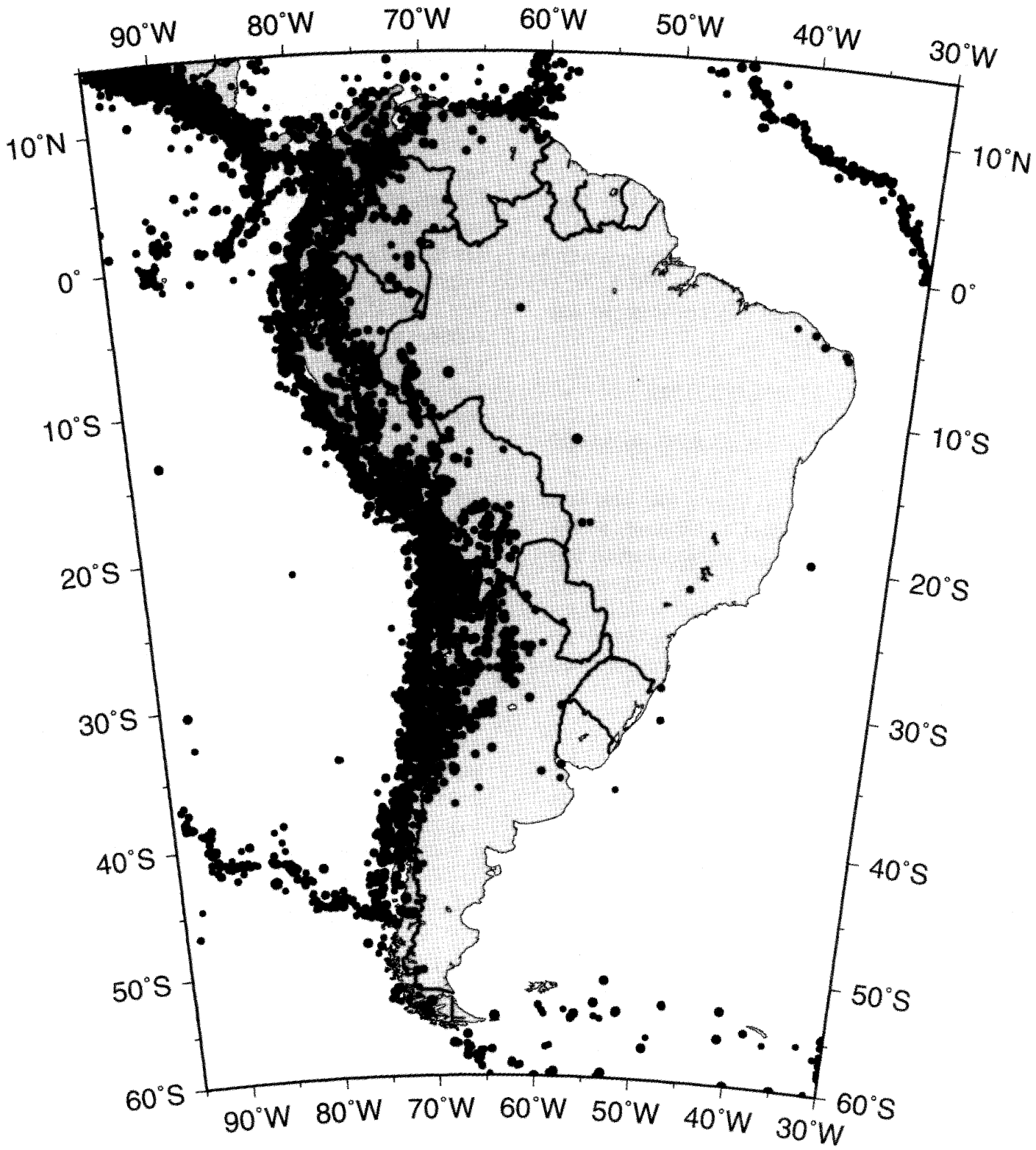

Fig. 5. The locations of damaging earthquakes used to determine the seismic hazard in South America. Earthquakes with $\boldsymbol{M} \geq 4.6$ that occurred during the years 1900 through 1994 are plotted. Symbol sizes correspond to $\boldsymbol{M}$. 


\subsection{Strong ground motion relationships}

The reference site condition for the hazard map of South America is «rock». This corresponds to class A of the Boore et al. (1993) classification scheme, class A of the National Earthquake Hazard Reduction Program (NEHRP; 1994) classification scheme, and «rock» or «hard rock» in all other schemes.

PGA was calculated using two strong ground motion attenuation relationships. PGA from earthquakes shallower than $15 \mathrm{~km}$ was estimated using the relationship

$$
\begin{gathered}
\log A=-1.229+0.227 \boldsymbol{M}- \\
-\log \left(D^{2}+44.225\right)^{0.5}-0.0023\left(D^{2}+44.225\right)^{0.5}
\end{gathered}
$$

where $D$ is the distance to the rupture and $\boldsymbol{M}$ is moment magnitude (Joyner and Boore, 1993). The PGA attenuation relationship used to estimate ground motion form all other earthquakes avoids rapid attenuation of ground motion near the earthquake epicenter through explicit inclusion of the half-width (RD) of the rupture zone (Singh et al., 1982)

$$
\mathrm{RD}=0.5\left(10^{M-4}\right)^{1 / 2}
$$

where $\mathrm{RD}=$ distance from the epicenter to the edge of the rupture zone, and $\boldsymbol{M}$ is the moment magnitude of the earthquake. RD (the near field) was limited to a maximum value of $37 \mathrm{~km}$ for the calculation of hazard. PGA was estimated using the relationship

$$
\ln A=-1.687+0.553 M-0.537 \ln R-0.00302 R
$$

where $R$ is either the depth to the hypocenter if $R<\mathrm{RD}$ or the distance from the point to the edge of the rupture zone if $R \geq \mathrm{RD}$, and $\boldsymbol{M}$ is moment magnitude (Climent et al., 1994).

\subsection{Hazard computation method}

The seismic hazard values for a $0.5^{\circ}$ by $0.5^{\circ}$ grid across South America were calculated using the historic parametric method (Veneziano et al., 1984; McGuire, 1993), as applied by
Tanner and Shepherd (1997). The first step is the development of a uniform earthquake cata$\log$ for the region. Next, appropriate attenuation functions are identified or developed. Estimates of ground motion from every earthquake in the catalog are calculated at every site in the region based on the chosen attenuation function(s). Return periods for exceedance of a range of values of ground motion are tabulated, and curves are fit to these data. The curves are extrapolated to estimate the value of the ground motion (in this case, PGA) for the return period of interest (approximately 475 years) at each site. Details of the method may be found in several publications (Veneziano et al., 1984; McGuire, 1993; Tanner and Shepherd, 1997).

\subsection{Results and discussion}

Uncertainty was explicitly included in PAIGH South America hazard calculations. All input parameters were assumed to be normally distributed except attenuation and depth, which were assumed to be log-normally distributed. The software developed by Tanner and Shepherd (1997) used a pseudo-random number generator to scale the standard deviations assigned to each parameter. Median PGA values at each site were calculated after a minimum of 100 iterations through the range of parameter variations.

The seismic hazard map of South America depicts the median PGA with a $10 \%$ probability of exceedance in 50 years (fig. 6). The $0.5^{\circ}$ by $0.5^{\circ} \mathrm{PAIGH}$ and PILOTO grids of values were interpolated and resampled to a $0.1^{\circ}$ by $0.1^{\circ}$ grid using GMT software (Wessel and Smith, 1995). The grids were combined as follows (fig. 7):

- PILOTO values were unaltered for the Andean region.

- PAIGH values were unaltered for southern and eastern South America

- PILOTO values were smoothed into PAIGH values in the merge region.

The smoothing function was of the form

$$
\mathrm{PGA}=d a+(1-d) b
$$

where $a=$ the PAIGH PGA value, $b=$ the 

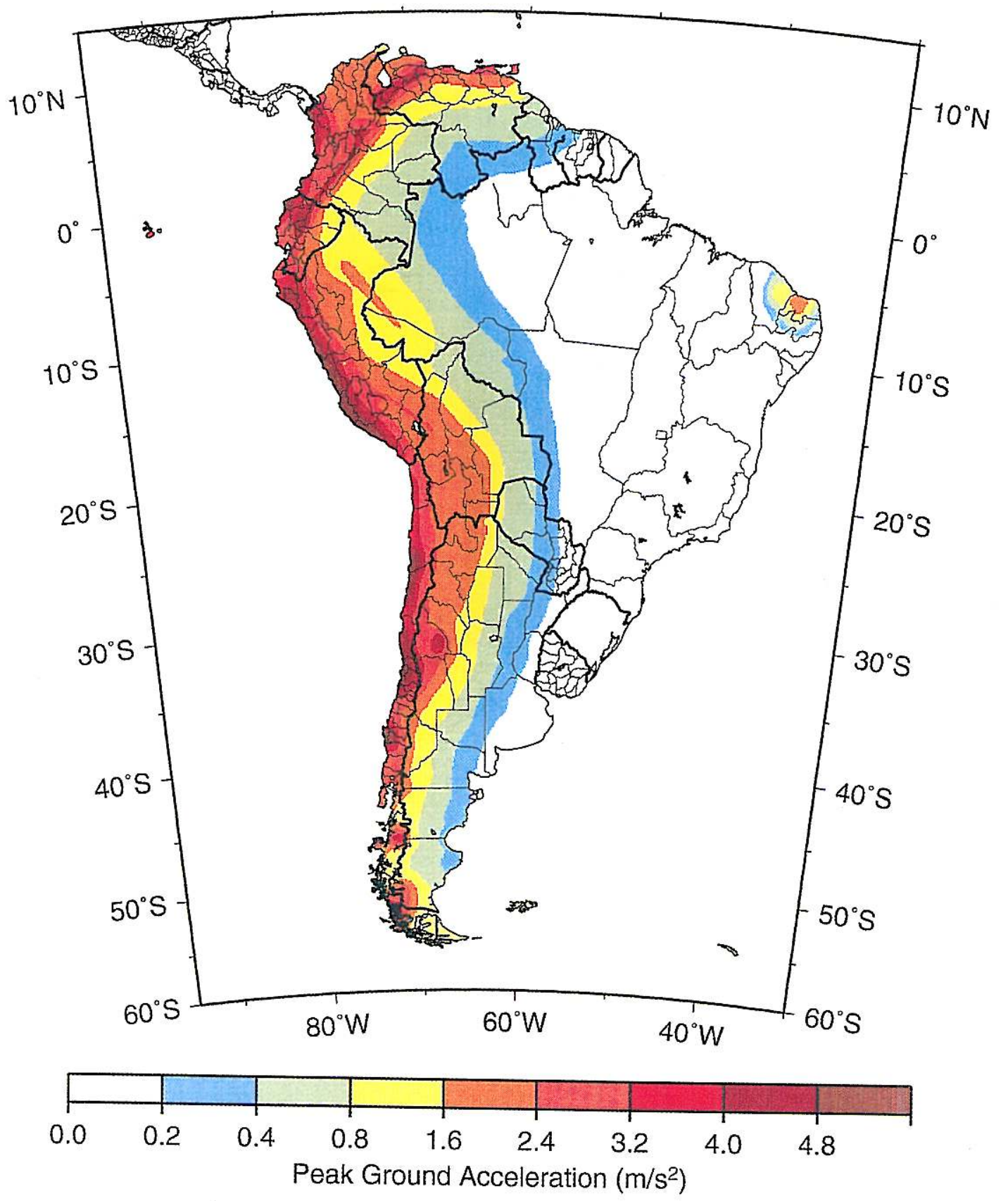

Fig. 6. The seismic hazard map of South America. PGA with a $10 \%$ chance of exceedance in 50 years is depicted in $\mathrm{m} / \mathrm{s}^{2}$. 


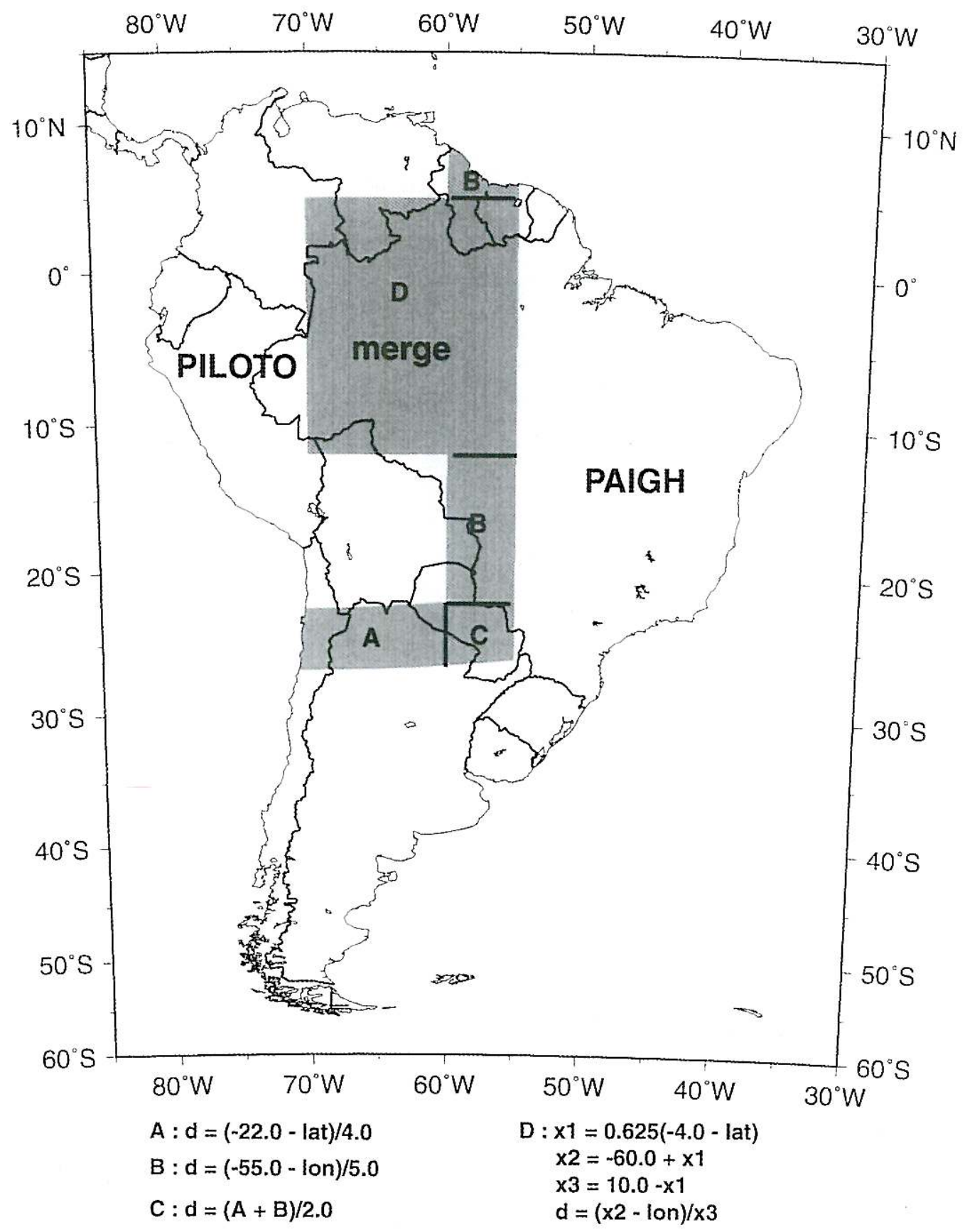

Fig. 7. The PGA maps calculated by PAIGH and PILOTO were combined into a single PGA map of South America. The values calculated by each group are the mapped values in the marked, unshaded regions. The shaded merge zone has boundaries at $26^{\circ} \mathrm{S}, 22^{\circ} \mathrm{S}, 12^{\circ} \mathrm{S}, 5^{\circ} \mathrm{N}, 70^{\circ} \mathrm{W}, 60^{\circ} \mathrm{W}$, and $55^{\circ} \mathrm{W}$. 


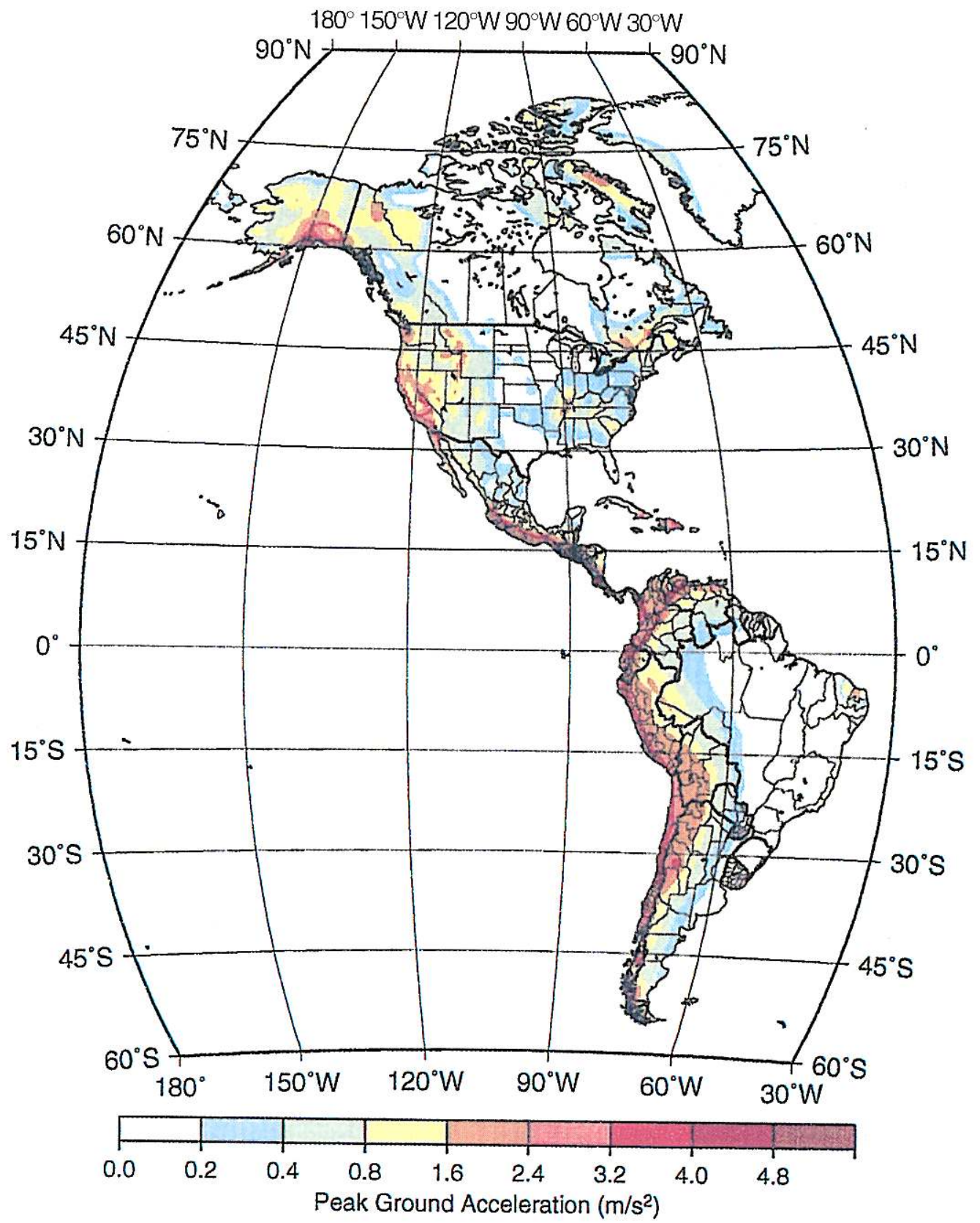

Fig. 8. The seismic hazard map of the Americas depicting Peak Ground Acceleration (PGA), given in units of $\mathrm{m} / \mathrm{s}^{2}$, with a $10 \%$ chance of exceedance in 50 years. The site classification is rock everywhere except Canada and the United States, which assume «rock/firm soil» reference ground conditions. The return period for Mexico is 500 years. The return period for all other countries is 474.56 years. 
PILOTO PGA value, and $d=0$ along the west boundary of the merge zone and $d=1$ along the east and south boundary of the merge zone. The linear operator $d$ varied with latitude, longitude, or both, and was recalculated in $0.1^{\circ}$ steps in each direction (fig. 7).

The highest seismic hazard values are along the west coast of South America, coincident with the subduction of the Cocos and Nazca plates beneath the Caribbean and South American plates. The highest hazard values are due to the possibility of the repeat of the 1960 Chilean earthquake. High hazard values are due to the possibilities of repeats of any of the large $(\boldsymbol{M}>8)$ damaging earthquakes anywhere along the west coast of South America.

Improvements in future maps will involve inclusion of scenario events for South America, updated regionally appropriate ground motion relationships, increases in the amount and bandwidth of recorded earthquake data, and the production of several SA maps.

\section{Western hemisphere}

The seismic hazard maps of North and Central America and the Caribbean (Shedlock, 1999) and South America (fig. 6) have been combined to form the seismic hazard map of the western hemisphere (fig. 8). The seismic hazard map of the Americas depicts PGA with a $10 \%$ chance of exceedance in 50 years. The site classification is rock everywhere except Canada and the United States, which assume rock/firm soil reference ground conditions. PGA calculated for rock/firm soil sites will be larger than PGA calculated for rock sites for a given earthquake. Thus, the PGA values calculated for Canada and the United States are systematically larger ( $\leq 25 \%$ larger) than PGA values calculated for México, Central and South America, and the Caribbean. The return period for Mexico is 500 years. The return period for all other countries is 475 years. This seismic hazard map of the Americas depicts the shaking hazard that will have the largest effect on one to two story structures (the largest class of structures in the Americas).

The areas of greatest hazard are along the subduction plate boundaries of Alaska, Central
America, South America, the Eastern Caribbean and México, the transform plate boundaries of the Northern Caribbean and Western U.S., and the southeast coast of Hawaii. Although Hawaii is not near a plate boundary, it is a 'hot-spot', where whole-plate (rather than intraplate) tectonic processes dominate.

In general, the energy release in large subduction zone earthquakes is much greater than the energy release in transform fault (strikeslip) earthquakes. The 1960 Chile ( $M$ 9.5) and the 1964 Alaska ( $M$ 9.2) subduction zone earthquakes are the largest earthquakes ever recorded. Nonetheless, the highest hazard value calculated in the Americas is in Southern California (U.S.), along the San Andreas fault (even when reduced to match the site classification of other countries). Large subduction zone earthquakes are deep (many tens to hundreds of kilometers) and the subduction zones along the west coast of the Americas are tens to hundreds of kilometers offshore. Thus, energy released in a large subduction zone earthquake has begun to attenuate before it reaches onshore population centers. Earthquakes along the San Andreas fault (and transform faults in general) are shallow $(<20 \mathrm{~km})$ and often involve surface rupture. The San Andreas fault is onshore for much of its length, and passes through Southern California. Thus, energy released in a large San Andreas fault earthquake passes through population centers immediately, producing a higher shaking hazard.

Exposure and vulnerability to the effects of earthquakes is increasing as urban centers grow, especially in tectonically active areas. The economic and social effects of earthquakes can be reduced through a comprehensive assessment of seismic hazard and risk that leads to increased public awareness, seismically sensitive land-use planning, and the implementation of seismically sound building construction codes. Probabilistic seismic hazard maps serve as the bases of building design maps in many of the countries of the Americas. These PGA maps and supporting documentation are designed to provide a useful global seismic hazard framework and serve as a resource for any national or regional agency for further detailed studies applicable to their needs. 


\section{Acknowledgements}

This seismic hazard maps of South America and the Americas are the result of decades of work and the contributions of hundreds of scientists and technical personnel, as well as universities and public and private agencies and organizations. Although it is impractical name everyone, we are grateful to every contributor. In particular, we are grateful to John Adams, Cristina Dimaté, Art Frankel, Steven Halchuk, Walter Montero, John Shepherd, and Ramon Zúñiga. Thanks to P. Wessel and W.H.F. Smith for developing GMT, which we used to produce figs. 1, 3, and 5-8 in this text. The principle authors (and affiliations) of the authors of the maps combined to produce this map are listed under «Contact Information» (below). Many more contributors are listed in the «References» section.

\section{Contributors and contact information}

This seismic hazard map of the Americas is the result of decades of work and the contributions of hundreds of scientists and technical personnel, as well as universities and public and private agencies and organizations, throughout the Americas. The principal authors (and affiliations) of the maps combined to produce this map are:

\section{Canada}

J. Adams, D.H. Weichert, S. Halchuk and P. Basham Geological Survey of Canada

Contact:

John Adams (adams@seismo.nrcan.gc.ca)

Stephen Halchuk (halchuk@seismo.nrcan.gc.ca)

Geological Survey of Canada

1 Observatory Crescent

Ottawa, ON, K1A 0Y3, Canada

\section{Central America and the Caribbean}

Walter Montero P., Giovanni Peraldo H. and Wilfredo

Rojas Q.

Universidad de Costa Rica

J.G. Tanner ${ }^{1}$, J.B. Shepherd ${ }^{2}$, C.M. McQueen ${ }^{2}$ and L.L. Lynch ${ }^{3}$

University of Western Ontario ${ }^{1}$, University of Lancaster ${ }^{2}$ and University of the West Indies ${ }^{3}$

Contact:

Walter Montero P. (wmontero@cariari.ucr.ac.cr)

Escuela Centroamericana de Geologia
Universidad de Costa Rica

Apartado 35-2060

San José, Costa Rica

James G. Tanner (jtanner@execulink.com)

IPGH

R.R. \#1

Union, ON, NOL 2L0, Canada

\section{México}

R. Zúñiga, G. Suárez, M. Ordaz and V. García-Acosta Universidad Nacional Autonoma de Mexico

Contact:

Ramon Zúñiga (ramon@ollin.igeofcu.unam.mx)

Instituto de Geofisica

UNAM

Cd. Universitaria

Coyoacán, México 04510, D.F., México

\section{South America}

Larry A. Drake - Observatorio San Calixto, Bolivia M. Cristina Dimaté C. - INGEOMINAS, Colombia Hugo Yepez - Escuela Politecnica Nacional, Ecuador Leonidas Ocola - Instituto Geofisica del Perú

Herbert Rendon - FUNVISIS, Venezuela

J.G. Tanner - University of Western Ontario

J.B. Shepherd - University of Lancaster

Contact:

M. Cristina Dimaté C.

(cdimate@ametista.ingeomin.gov.co)

INGEOMINAS

Diagonal 53 N. 34-53

Santsfè de Bogotà, Colombia

James G. Tanner (jtanner@execulink.com)

IPGH

R.R. \#1

Union, ON, NOL 2L0, Canada

\section{United States}

A. Frankel, R. Wesson, C. Mueller, F. Klein, T. Barnhard, D. Perkins, E.V. Leyendecker, N. Dickman, S. Harmsen, S. Hanson and M. Hopper

United States Geological Survey

Contact:

Art Frankel (afrankel@usgs.gov)

USGS

MS 966 Box 25046

Denver, CO 80225, U.S.A.

\section{REFERENCES}

ABRAHAMSON, N.A. and K.M. SHEDLOCK (1997): Overview, Seismol. Res. Lett., 68, 9-23.

AKI, K. and P.G. RICHARDS (1980): Quantitative Seismology: Theory and Methods, I (W.H. Freeman, San Francisco), pp. 557. 
ANDERSON, J.G. (1997): Nonparametric description of peak acceleration above a subduction thrust, Seismol. Res. Lett., 68, 86-93.

BOORE, D.M., W.B. JOYNER and T.E. FuMAL (1993): Estimation of response spectra and peak accelerations from Western North American earthquakes: an interim report, U.S. Geol. Surv. Open-File Rep. 93-509, p. 72.

Boore, D.M., W.B. JOYNER and T.E. FuMAL (1994): Estimation of response spectra and peak accelerations from Western North American earthquakes: an interim report Part 2, U.S. Geol. Surv. Open-File Rep. 94-127, p. 40 .

BORCHERDT, R.D. (1993): Simplified site classes and empirical amplification factors for site-dependent code provisions, in Proceedings International Workshop Strong Motion Data, Part and Harbor Res. Inst., Kanagawa, 2, 399-427.

CAmpBelL, K.W. and Y. Bozorgnia (1994): Near-source attenuation of peak horizontal acceleration from worldwide recorded from 1957 to 1993, in Proceedings Fifth U.S. National Conference Earthquake Engineering, EERI, 3, 283-292.

Climent, A., W. Taylor, M.C. Real, W. Strauch, G. SANTANA, M. VillagRan, A. DAHLE and H. Bungam (1994): Spectral strong motion attenuation in Central America, NORSAR Tech. Rep. 2-17, pp. 46.

CORNELL, C.H. (1968): Engineering seismic risk analysis, Bull. Seismol. Soc. Am., 58, 1583-1606.

CRouse, C.B. (1991): Ground motion attenuation equations for earthquakes on the Cascadia subduction zone, Earthquake Spectra, 7, 201-236.

Dimaté, C., L. DRAKe, H. YePeZ, L. OCOla, H. RENDON, G. GRÜNTHAL and D. GIARDINI (1999): Seismic hazard assessment in the Northern Andes (PILOTO Project), Ann. Geofis., 42 (6), 1039-1055 (this volume).

JOYNER, W.B. and D.M. BOORE (1993): Methods of regression analysis of strong motion data, Bull. Seismol. Soc. Am., 83, 469-487.

KANAMORI, H. (1977): The energy release in great earthquakes, J. Geophys. Res., 82, 2981-2987.

MCGUIRE, R.K. (1993): Computation of seismic hazard, in Global Seismic Hazard Assessment Program, edited by D. Giardini and P.W. BASHAM, Ann. Geofis., 36 (3-4), 181-200.

NEHRP (1994): Recommended provisions for the development of seismic regulations for new buildings, prepared by Building Seismic Safety Council for Federal Emergency Management Agency, Washington, D.C.

SHEDLOCK, K.M. (1999): Seismic hazard map of North and Central America and the Caribbean, Ann. Geofis., 42 (6), 977-997 (this volume).

SHEDLOCK, K.M. and N.A. ABRAHAMson (1997): Ground motion attenuation in subduction zones, in Proceedings Earthquakes - Converging at Cascadia, AEG Spec. Publ., 10, 79-87.

SingH, S.K., R. APSEL, J. Fried and J.N. BRUNE (1982): Spectral attenuation of $S H$-waves along the Imperial Fault, Bull. Seismol. Soc. Am., 72, 2003-2016.

TANNER, J.G. and J.B. SHEPHERD (1997): Seismic hazard in Latin America and the Caribbean, in Project Catalog and Seismic Hazard Maps, IRDC, Ottawa, vol. 1, p. 143.

Veneziano, D., C.A. Cornell and T. O'Hara (1984): Historical method of seismic hazard analysis, Elect. Power Res. Inst. Rep. NP-3438, Palo Alto.

WESSEL, P. and W.H. SMITH (1995): GMT version 3 technical reference and cookbook, NOAA N/OES12, pp. 92. 